Article

\title{
On the Tortuosity of TPMS Scaffolds for Tissue Engineering
}

\author{
Rafael Guerreiro, Tiago Pires $\mathbb{D}^{\mathbb{D}}$, José M. Guedes, Paulo R. Fernandes $\mathbb{D}$ and André P. G. Castro * $\mathbb{D}$
}

IDMEC, Instituto Superior Técnico, Universidade de Lisboa, 1049-001 Lisboa, Portugal; rafael.guerreiro@tecnico.ulisboa.pt (R.G.); tiago.a.h.v.pires@tecnico.ulisboa.pt (T.P.); jmguedes@tecnico.ulisboa.pt (J.M.G.); paulo.rui.fernandes@tecnico.ulisboa.pt (P.R.F.)

* Correspondence: andre.castro@tecnico.ulisboa.pt

Received: 5 March 2020; Accepted: 2 April 2020; Published: 9 April 2020

\begin{abstract}
Recently, bone tissue engineering (TE) has seen new developments, with triply periodic minimal surfaces (TPMSs) being used to develop new porosity-controlled scaffolds to interface new tissue growth. The process of choosing the best geometry to a specific application still lacks research, so the goal for this work is to propose a new method of scaffold selection, based on assessing the tortuosity inside these symmetric TPMS-based structures. Additionally, computer fluid dynamic (CFD) simulations were conducted to validate this method. The comparison between tortuosity and CFD outputs suggests that an analysis of the tortuosity could be used as an early indicator of the scaffold's viability for specific applications, favouring scaffolds with more intricate and curvature-dependent streamlines.
\end{abstract}

Keywords: tissue engineering; TPMS scaffolds; tortuosity; computational fluid dynamics; permeability; homogenisation method

\section{Introduction}

Tissue engineering (TE) scaffolds are porous structures used to promote the growth of a new tissue. Properties like pore size, material, and equivalent stiffness, as well as the curvature of the interconnected pores, are key factors to ensure an adequate cell adhesion and proliferation [1-4].

Concerning bone TE applications, scaffolds should be able to provide not only the mechanical support needed for the growth of new bone, but also an adequate micro environment that allows for cell adhesion and differentiation into new bone cells [5,6]. In other words, the scaffolds shall act as an interface for bone growth and/or remodelling [7-9].

Common techniques like optimization, as well as top-down and bottom-up approaches, have been used in the development of new scaffolds $[10,11]$. More recently, triply periodic minimal surfaces (TPMSs) have also been used to develop porous structures with interconnected pores, good stiffness, and a high ratio of surface area per volume fraction [1,12]. Scaffolds obtained by this method have shown an enhanced potential for cell migration and a high level of mechanical support $[13,14]$. This means that different periodic geometries can be developed as a function of the target tissue, parting from this source formulation $[15,16]$.

This adaptability of TPMS-based scaffolds is particularly relevant as the main goal when developing a new scaffold is to mimic the structures of the target tissue, thus allowing for the regeneration or formation of that tissue. If one focuses on bone regeneration and formation, the osteoblasts shall have sufficient seeding area and be subjected to adequate mechanical stimuli to proliferate, and thus generate bone. The porosity and permeability of a given scaffold are among the major players in generating this appropriate environment, so it is of major importance to fully comprehend the characteristics of each scaffold [14,17-19]. Beyond these usual metrics, tortuosity is proposed here as a 
predictable application-specific factor for scaffold design; tortuosity is defined as the relation between the preferential fluid flow path inside the scaffold and the curvature of its porous structure, which means that it strongly influences the permeability of the structure as a function of its porosity [20-22].

The objective of this work is to propose a new method of selecting a TPMS scaffold for a specific application, based on a curvature analysis through the tortuosity of the structure. In other words, this work intends to present a faster approach to scaffold selection as a function of the relation between its porous structure and fluid permeation behaviour. Thus, this method allows for a primary scaffold design screening, providing an initial viability report and excluding geometries with non-suitable behaviour for the desired application, before performing computational fluid dynamics (CFD) analysis and experimental measurements. Using this analytical approach, those time-consuming method can be employed only in later project stages.

\section{Materials and Methods}

This work focuses on the evaluation of three different TPMS structures: Schwarz D (SD), Gyroid (SG), and Schwarz P (SP) [23]. These geometries have been studied for multiple bone TE applications, especially as substitutes for trabecular bone $[5,14]$. The scaffolds were created using a custom TPMS generator, which crafts the basic geometry of these structures based on structural design, porosity, and layer thickness. Four different porosities were considered (50\%, 60\%, 70\%, and 80\%) for each TPMS geometry (SD50 to SP80), following the range of porosities recommended for biomedical applications found in the literature [22,24,25]. The output is the finite element (FE) mesh of the scaffold [13], in this case, with $3.25 \times 3.25 \times 3.25 \mathrm{~mm}$ and 40 elements on each side, in order to comply with a previous experimental study [23]. Three different numerical methods were used to study these geometries: analysis of the tortuosity, homogenisation of the permeability coefficients, and CFD analysis.

\subsection{Permeability Calculation}

The first part of this work consisted of calculating the permeability for the twelve scaffold models, in order to characterise the potential of each one of these models to allow for a consistent fluid flux $[14,23,26]$. Each geometry is named after the structure and its porosity, for example, SD50 refers to the SD scaffold with $50 \%$ porosity.

The homogenisation method presented in the works of Guedes and Kikuchi [27] and Terada et al. [28] was used for this calculation, with its outputs being compared to those of a related CFD analysis. The homogenisation of the equivalent permeability coefficients is a faster way of characterising these periodic porous structures, as happens with the analogous homogenisation of the equivalent elastic coefficients performed by other authors [13,29-31].

The CFD simulations were performed with 16.2 ANSYS FLUENT Solver (Ansys Inc. USA), which has proven to be effective in scaffold analysis [32]. The simulations were performed with an inlet flow rate of $5 \mathrm{~mL} / \mathrm{min}$ to ensure a laminar flow; this flow rate has been shown to be in the relevant range for biomedical applications [24,33]. The CFD model used the inverse of the scaffold, which can also be considered as the substrate for cell adhesion and proliferation [23]. The permeability chamber had a squared cross section of $3.25 \times 3.25 \mathrm{~mm}$ and a total length of $23.5 \mathrm{~mm}$ (Figure 1). The permeability of the different scaffolds was calculated based on the pressure drop across the structure using the Darcy's Law [29], which can be expressed as follows:

$$
K=\frac{Q * \mu * L}{A * \Delta P}
$$

where $\mathrm{K}$ is the permeability in $\mathrm{m}^{2}, \Delta P$ is the pressure drop across the structure in $\mathrm{Pa}, \mathrm{L}$ is the length of the section in $\mathrm{m}, \mathrm{A}$ is the cross-sectional area of the flow in $\mathrm{m}^{2}, \mu$ is the dynamic viscosity of the fluid in $\mathrm{Pa}^{*} \mathrm{~s}$, and $\mathrm{Q}$ is the flow rate expressed in $\mathrm{m}^{3} / \mathrm{s}$. 


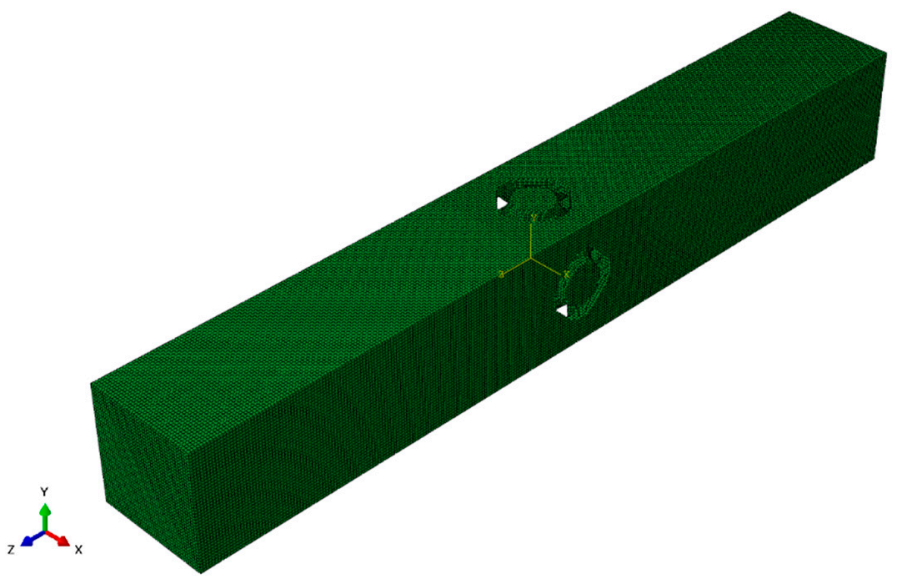

Figure 1. Finite element model of a Schwarz P 70 (SP70) unitary cell (with the chamber attached) used for the computational fluid dynamics (CFD) simulations.

In addition, boundary conditions had to be defined across the structure. For these simulations, two conditions were assumed: velocity-inlet and pressure-outlet. On the one hand, and as mentioned before, the velocity at the inlet was $5 \mathrm{~mL} / \mathrm{min}$. This defines where the fluid enters the structure and at what velocity. On the other hand, the pressure-outlet indicates where the fluid exits the structure and what is the pressure at those surfaces. For this work, this pressure was $0 \mathrm{~Pa}$.

\subsection{Tortuosity Analysis}

The tortuosity of each scaffold was analytically evaluated based on the location of each pore and its interconnectivity with the adjacent pores. To do so, the elements corresponding to the substrate (Figure 2) were first isolated from those that form the solid scaffold. Individual analyses were performed for each model.

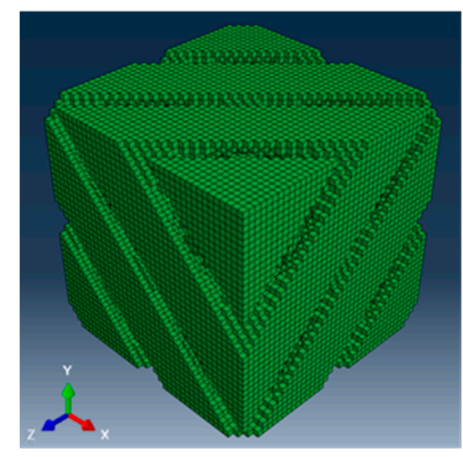

(a)

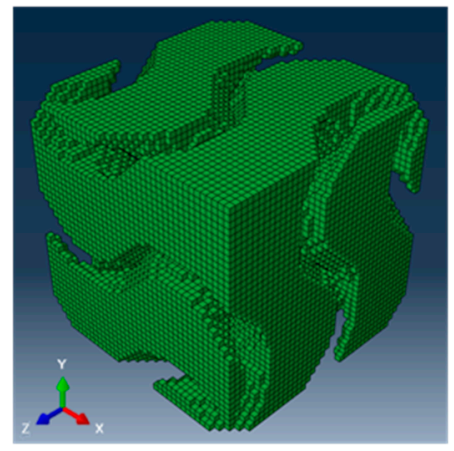

(b)

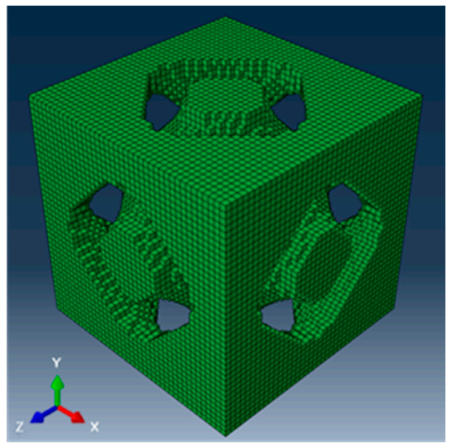

(c)

Figure 2. Finite element models of the substrates for the tortuosity analysis: (a) Schwarz D 70 (SD70); (b) Gyroid 70 (SG70); and (c) Schwarz P 70 (SP70).

After this first step, each slice of each geometry was analysed, and the centroids of the substrate elements were saved. Given the periodic nature of TPMS geometries, the number of individual paths inside the unitary cell depends on the geometry of the scaffold; while there is only one path crossing the interior of the SP70 geometries, the internal structures of SD70 and SG70 models permit multiple repetitive paths for the fluid flow. Therefore, for these two scaffold models, only a small area of each slice was considered in order to evaluate one of those repetitive paths.

In order to validate this new approach, the streamlines of the CFD simulations of these three models were compared with the outputs from the analytical tortuosity analysis, showing that this is valid for a laminar flow regime. 


\section{Results}

\subsection{Permeability Calculation}

Table 1 illustrates the permeability coefficients obtained for the different geometries and porosities, comparing the homogenisation method to the CFD simulations. The twelve models under study had similar permeabilities with both techniques. The SP geometry registered an increase in permeability of approximately $78 \%$ when increasing the porosity from $50 \%$ to $60 \%$, with this percentage being approximately $94 \%$ when comparing $50 \%$ with $80 \%$ porosities. The maximum increase for the other models was $72 \%$ (similar value for SD and SG).

Table 1. Permeability coefficients (in $\mathrm{mm}^{2}$ ) for the different structures and porosities obtained from homogenisation (HMG) and computational fluid dynamics (CFD) analysis. SD, Schwarz D; SG, Gyroid; SP, Schwarz P.

\begin{tabular}{|c|c|c|c|c|c|c|c|c|c|}
\hline & & \multicolumn{8}{|c|}{ Porosity } \\
\hline & & \multicolumn{2}{|c|}{$50 \%$} & \multicolumn{2}{|c|}{$60 \%$} & \multicolumn{2}{|c|}{$70 \%$} & \multicolumn{2}{|c|}{$80 \%$} \\
\hline \multirow{4}{*}{ Geometry } & Method & HMG & CFD & HMG & CFD & HMG & CFD & HMG & CFD \\
\hline & SD & $3.51 \times 10^{-3}$ & $3.37 \times 10^{-3}$ & $5.79 \times 10^{-3}$ & $5.62 \times 10^{-3}$ & $8.96 \times 10^{-3}$ & $8.88 \times 10^{-3}$ & $1.27 \times 10^{-2}$ & $1.28 \times 10^{-2}$ \\
\hline & SG & $5.86 \times 10^{-3}$ & $6.07 \times 10^{-3}$ & $9.75 \times 10^{-3}$ & $1.00 \times 10^{-2}$ & $1.46 \times 10^{-2}$ & $1.48 \times 10^{-2}$ & $2.11 \times 10^{-2}$ & $2.12 \times 10^{-2}$ \\
\hline & SP & $1.19 \times 10^{-3}$ & $1.23 \times 10^{-3}$ & $5.35 \times 10^{-3}$ & $5.52 \times 10^{-3}$ & $1.20 \times 10^{-2}$ & $1.26 \times 10^{-2}$ & $2.08 \times 10^{-2}$ & $2.18 \times 10^{-2}$ \\
\hline
\end{tabular}

Figure 3 illustrates the variation of the permeability coefficients over the different porosities for the four models. The outputs from both the homogenisation method and the CFD simulations are shown.

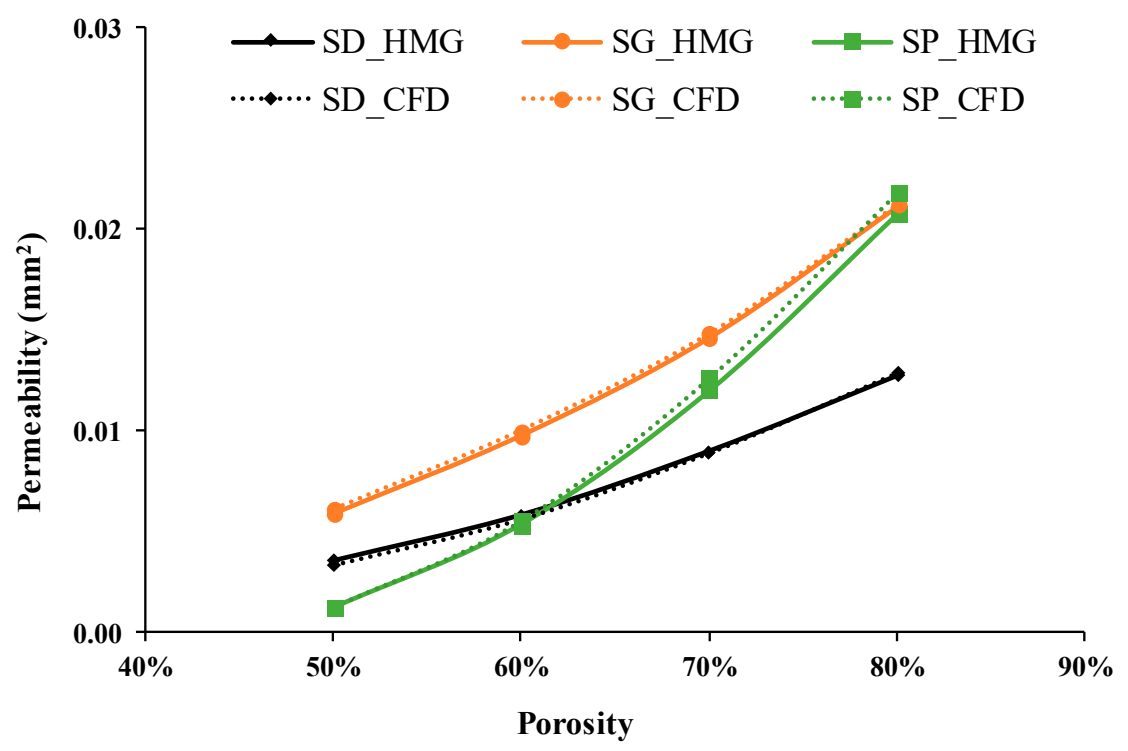

Figure 3. Coefficients of permeability (in $\mathrm{mm}^{2}$ ) for the homogenisation (HMG) and computational fluid dynamics (CFD) techniques, as a function of the porosity analysis, for the twelve models under analysis.

As seen in Figure 3, both tecnhiques used in this study presented similar results for the different geometries. For all the porosities considered, the highest coefficients of permeability were obtained for the SG geometry. The only exception was found for the $80 \%$ porosity, when comparing the SG and SP geometries using the CFD method.

\subsection{Tortuosity Analysis}

The paths inside each scaffold were studied in order to better understand the influence of each geometry and its relation to possible TE applications. It was found that the tortuosity did not change 
across the four different porosities, that is, the preferential paths for fluid permeation revealed by the tortuosity analysis were not influenced by the porosity, for the three TPMS geometries.

Therefore, only the scaffolds with 70\% of porosity (SD70, SG70, and SP70) are shown here. Figures 4-6 show the results obtained for the tortuosity of each scaffold as well as each individual geometry. The paths for the three structures are significantly different. It is particularly noticeable that only paths corresponding to straight lines were obtained for SP70, that is, the streamline for SP70 goes straight from the inlet to the outlet. The streamlines for SG70 and SD70 structures displayed more intricate paths, as these geometries have a much more complex configuration.

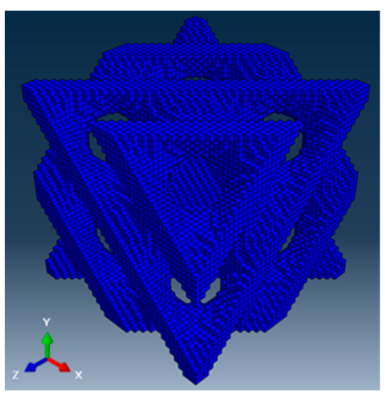

(a)

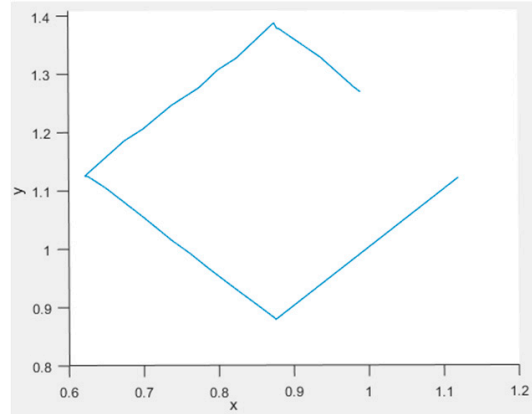

(b)

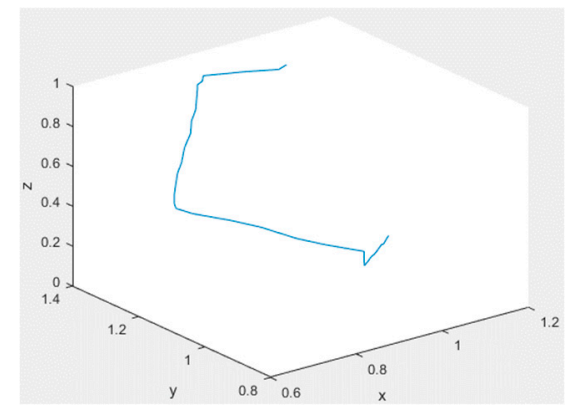

(c)

Figure 4. Tortuosity analysis of SD70: (a) isometric view of the porous structure; (b) and (c) top and isometric view of the path.

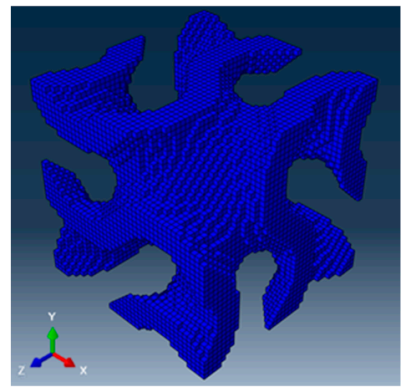

(a)

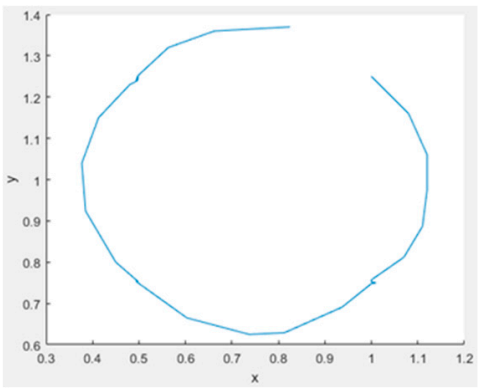

(b)

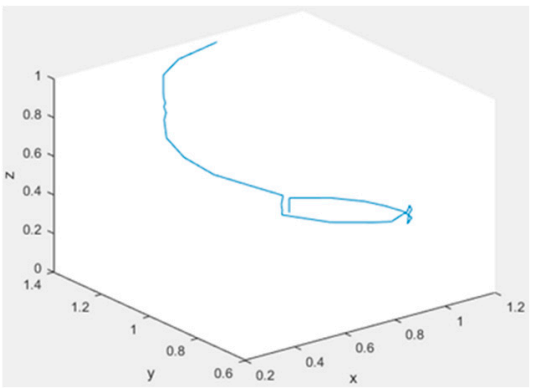

(c)

Figure 5. Tortuosity analysis of SG70: (a) isometric view of the porous structure; (b) and (c) top and isometric view of the path.

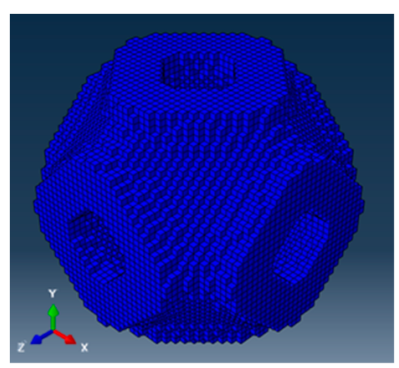

(a)

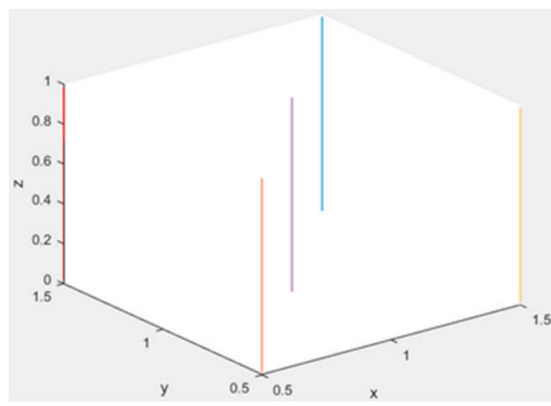

(b)

Figure 6. Tortuosity analysis of SP70: (a) isometric view of the porous structure; (b) isometric view of the path. 
Figure 7 illustrates the CFD streamlines obtained for each scaffold, with an inlet flow rate of $5 \mathrm{~mL} / \mathrm{min}$ (laminar flow regime), which are correlated with the streamlines predicted in Figures 4-6; that is, multiple intricate paths for SD70 and SG70, but a single preferential path for SP70.

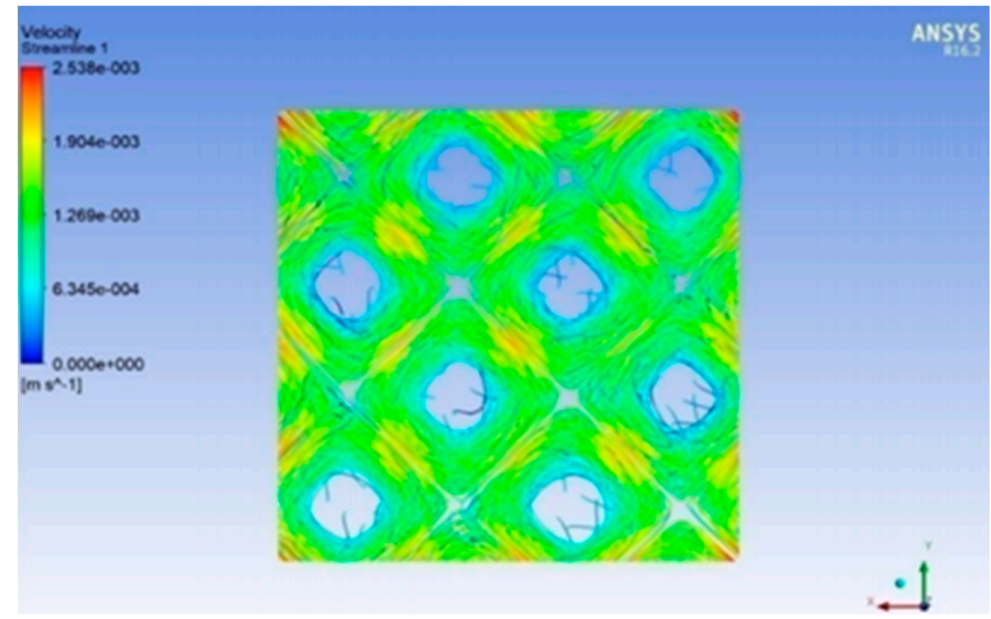

(a)

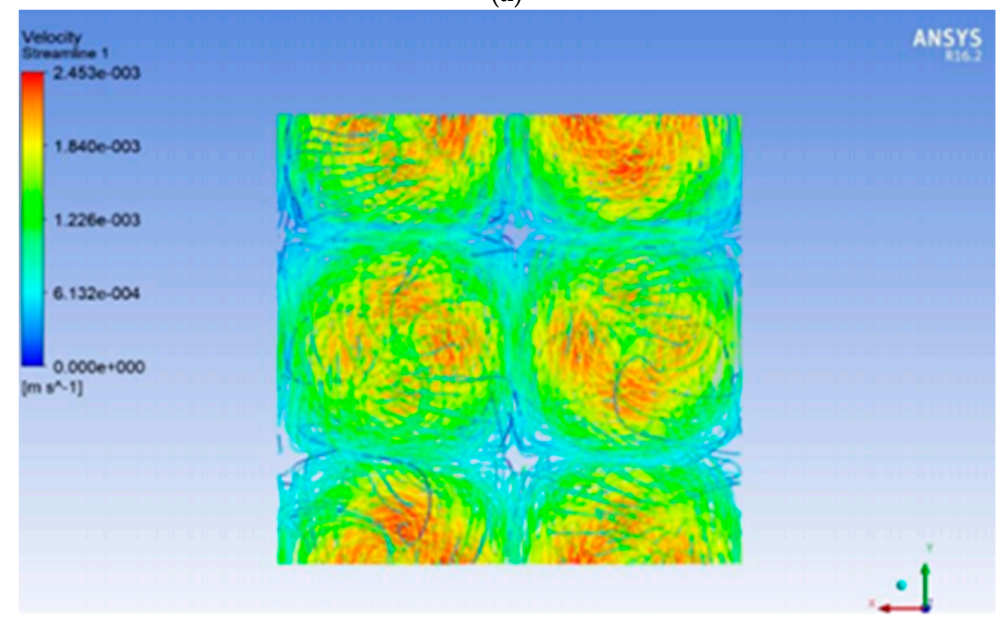

(b)

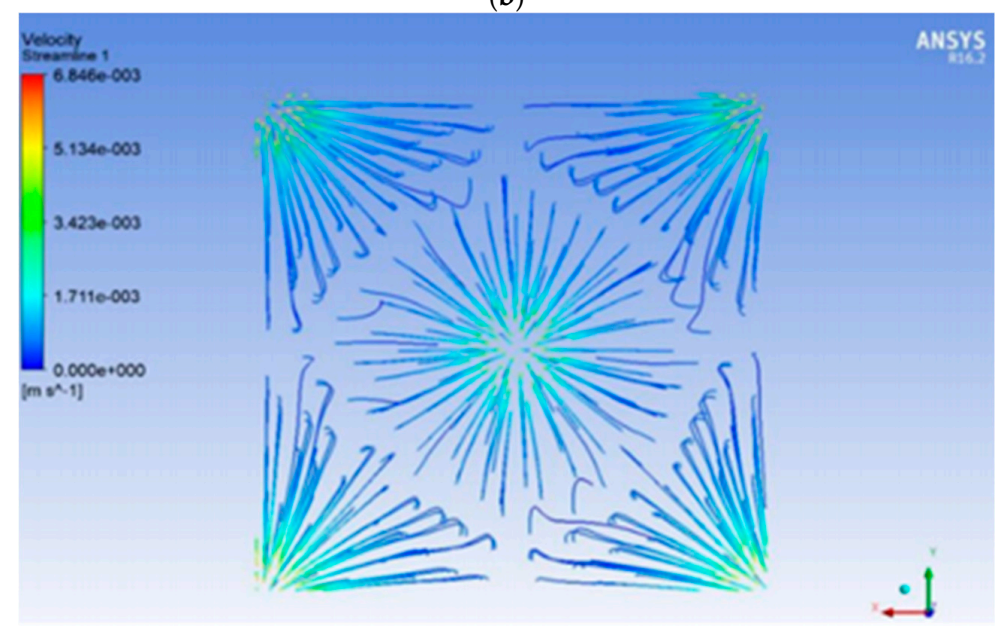

(c)

Figure 7. Top view of the streamlines observed on the CFD simulations, showing the preferential paths for fluid permeation throughout the scaffolds: (a) SD70; (b) SG70; and (c) SP70. 


\section{Discussion}

The main goal of the present work was to predict the flow paths inside three different scaffold geometries, by means of an innovative tortuosity analysis, complemented with CFD simulations for model validation. The obtained outputs in terms of internal fluid flow paths suggest that this type of analysis is useful for scaffold selection before performing time-consuming CFD simulations.

As demonstrated in Figures 4-6, each geometry presented a different path; that is, linear paths for the SP, squared helixes for the SD scaffolds, and circular helixes for the G. As expected, each scaffold has its own specific paths, independent of the porosity level, which may suggest that some geometries would be more suitable for some applications than others (i.e., cortical bone versus trabecular bone).

Regarding the results from the CFD simulations shown in Figure 7, the paths are in accordance with what was expected. As previously mentioned, both the SD and the SG geometries present a repetition of the same path multiple times within a single unitary cell. Moreover, the paths observed are identical to what was described above. On the one hand, SP presents linear paths, which expand in the interconnected areas between unitary cells. On the other hand, the SG geometry shows squared helixes with areas of connection between the paths. Finally, SD also presents areas of connection between multiple paths. However, unlike the SG structures, the paths are circular helixes.

By observing the paths across the three geometries, SP seems to be the most favourable for fluid passage because it shows a straight path for the fluid. However, this fact also suggests that the fluid is most likely not permeating a large volume of the scaffold, that is, the fluid is not reaching the internal curved surfaces. As a consequence, when proceeding to cell seeding, no cells would flow to or be seeded in these areas [32]. Additionally, the curved areas of these SP models correspond to the connections between the adjacent unitary cells (laterally). As the fluid flow would be perpendicular to the surface of the scaffold in those regions, these connection areas would probably be the more appealing ones for cell deposition and differentiation [14,34]. Subsequently, the existence of large "unused" areas combined with the linear paths of the SP geometry turn out in a smaller overall area of interaction between the walls of the scaffold and the cells.

Finally, the permeability coefficients obtained in both analyses (Table 1) prove that this homogenisation method is a useful tool for determining the permeability of a structure, as well as to study the influence of different parameters in the permeability of a scaffold, while avoiding time-consuming experimental tests, as suggested by other authors [29,31]. It is also noticeable that permeability and tortuosity are not directly linked, as the latter does not change with the porosity level, but it is true that the tortuosity helps define the permeability; in this analysis, the SP structures are greatly affected by the pore's geometry and extension, particularly in the swift increase of permeability from $50 \%$ to $60 \%$, which is not seen with the other geometries.

\section{Conclusions}

This work investigated a new method of scaffold selection based on the tortuosity of the different geometries. Both sets of results (tortuosity analysis and CFD simulations) showed similar paths for each of the three geometries being studied (SD, SP, and SG). Thus, this method gives a good perspective over the use of the tortuosity as an important feature for scaffold selection, particularly for bone TE applications [16,22].

The inclusion of the homogenisation analysis was also useful for the understanding of how each geometry depends on the porosity. The porosity of the SP geometry strongly influences the fluid passage, that is, the permeability has the steepest increased of the three models when going from $50 \%$ to $80 \%$ porosity. In addition, for all of the porosities studied here, the SP geometries will have a large percentage of their internal volume not being permeated by the fluid, which would thus be regions with little probability for cell adhesion and proliferation. As both SD and SG geometries are less susceptible to porosity variations and promote fluid streamlines within the whole structure, these will be more suitable for curvature-dependent TE applications. 
Author Contributions: Conceptualization, A.P.G.C. and P.R.F.; Methodology, A.P.G.C. and R.G.; Software, J.M.G., T.P., and R.G.; Validation, A.P.G.C., P.R.F., and J.M.G.; Formal analysis, A.P.G.C. and P.R.F.; Investigation, R.G.; Resources, P.R.F.; Data curation, T.P. and R.G.; Writing-original draft preparation, R.G.; Writing-review and editing, A.P.G.C. and P.R.F.; Visualization, R.G.; Supervision, A.P.G.C. and P.R.F.; Project administration, P.R.F.; Funding acquisition, P.R.F. All authors have read and agreed to the published version of the manuscript. Please turn to the CRediT taxonomy for the term explanation.

Funding: This research was funded by Portuguese Science and Technology Foundation (FCT), through IDMEC, under LAETA project UIDB/50022/2020 and also through project PTDC/BBB-BMC/5655/2014.

Conflicts of Interest: The authors declare no conflict of interest.

\section{References}

1. Vijayavenkataraman, S.; Zhang, L.; Zhang, S.; Hsi Fuh, J.Y.; Lu, W.F. Triply Periodic Minimal Surfaces Sheet Scaffolds for Tissue Engineering Applications: An Optimization Approach toward Biomimetic Scaffold Design. ACS Appl. Bio Mater. 2018, 1, 259-269. [CrossRef]

2. Wang, S.; Liu, L.; Li, K.; Zhu, L.; Chen, J.; Hao, Y. Pore functionally graded Ti6Al4V scaffolds for bone tissue engineering application. Mater. Des. 2019, 168, 107643. [CrossRef]

3. Vetsch, J.R.; Betts, D.C.; Müller, R.; Hofmann, S. Flow velocity-driven differentiation of human mesenchymal stromal cells in silk fibroin scaffolds: A combined experimental and computational approach. PLoS ONE 2017, 12, 1-17. [CrossRef] [PubMed]

4. Egan, P.F.; Shea, K.A.; Ferguson, S.J. Simulated tissue growth for 3D printed scaffolds. Biomech. Model. Mechanobiol. 2018, 17, 1481-1495. [CrossRef]

5. Shi, J.; Yang, J.; Zhu, L.; Li, L.; Li, Z.; Wang, X. A Porous Scaffold Design Method for Bone Tissue Engineering Using Triply Periodic Minimal Surfaces. IEEE Access 2018, 6, 1015-1022. [CrossRef]

6. Byrne, D.P.; Lacroix, D.; Planell, J.A.; Kelly, D.J.; Prendergast, P.J. Simulation of tissue differentiation in a scaffold as a function of porosity, Young's modulus and dissolution rate: Application of mechanobiological models in tissue engineering. Biomaterials 2007, 28, 5544-5554. [CrossRef]

7. Ulrich, T.A.; Jain, A.; Tanner, K.; MacKay, J.L.; Kumar, S. Probing cellular mechanobiology in three-dimensional culture with collagen-agarose matrices. Biomaterials 2010, 31, 1875-1884. [CrossRef]

8. Christen, P.; Ito, K.; Ellouz, R.; Boutroy, S.; Sornay-Rendu, E.; Chapurlat, R.D.; van Rietbergen, B. Bone remodelling in humans is load-driven but not lazy. Nat. Commun. 2014, 5, 4855. [CrossRef]

9. Guyot, Y.; Papantoniou, I.; Luyten, F.P.; Geris, L. Coupling curvature-dependent and shear stress-stimulated neotissue growth in dynamic bioreactor cultures: A 3D computational model of a complete scaffold. Biomech. Model. Mechanobiol. 2016, 15, 169-180. [CrossRef]

10. Lu, T.; Li, Y.; Chen, T. Techniques for fabrication and construction of three-dimensional scaffolds for tissue engineering. Int. J. Nanomed. 2013, 8, 337-350. [CrossRef]

11. Boccaccio, A.; Uva, A.E.; Fiorentino, M.; Mori, G.; Monno, G. Geometry design optimization of functionally graded scaffolds for bone tissue engineering: A mechanobiological approach. PLoS ONE 2016, 11, e0146935. [CrossRef] [PubMed]

12. Lu, Y.; Zhao, W.; Cui, Z.; Zhu, H.; Wu, C. The anisotropic elastic behavior of the widely-used triply-periodic minimal surface based scaffolds. J. Mech. Behav. Biomed. Mater. 2019, 99, 56-65. [CrossRef] [PubMed]

13. Castro, A.P.G.; Ruben, R.B.; Gonçalves, S.B.; Pinheiro, J.; Guedes, J.M.; Fernandes, P.R. Numerical and experimental evaluation of TPMS Gyroid scaffolds for bone tissue engineering. Comput. Methods Biomech. Biomed. Eng. 2019, 22, 567-573. [CrossRef] [PubMed]

14. Ali, D.; Ozalp, M.; Blanquer, S.B.G.; Onel, S. Permeability and fluid flow-induced wall shear stress in bone scaffolds with TPMS and lattice architectures: A CFD analysis. Eur. J. Mech. B/Fluids 2020, 79, 376-385. [CrossRef]

15. Ambu, R.; Morabito, A.E. Porous scaffold design based on minimal surfaces: Development and assessment of variable architectures. Symmetry 2018, 10, 361. [CrossRef]

16. Shi, J.; Zhu, L.; Li, L.; Li, Z.; Yang, J.; Wang, X. A TPMS-based method for modeling porous scaffolds for bionic bone tissue engineering. Sci. Rep. 2018, 8, 7395. [CrossRef]

17. Egan, P.F. Integrated Design Approaches for 3D Printed Tissue Scaffolds: Review and Outlook. Materials 2019, 12, 2355. [CrossRef] 
18. Kemppainen, J.M.; Hollister, S.J. Differential effects of designed scaffold permeability on chondrogenesis by chondrocytes and bone marrow stromal cells. Biomaterials 2010, 31, 279-287. [CrossRef]

19. Wang, Y.; Cui, W.; Zhao, X.; Wen, S.; Sun, Y.; Han, J.; Zhang, H. Bone remodeling-inspired dual delivery electrospun nanofibers for promoting bone regeneration. Nanoscale 2019, 11, 60-71. [CrossRef]

20. Ashworth, J.C.; Best, S.M.; Cameron, R.E. Quantitative architectural description of tissue engineering scaffolds. Mater. Technol. 2014, 29, 281-295. [CrossRef]

21. Gariboldi, M.I.; Best, S.M. Effect of ceramic scaffold architectural parameters on biological response. Front. Bioeng. Biotechnol. 2015, 3, 1-11. [CrossRef] [PubMed]

22. Ali, D. Effect of scaffold architecture on cell seeding efficiency: A discrete phase model CFD analysis. Comput. Biol. Med. 2019, 109, 62-69. [CrossRef] [PubMed]

23. Castro, A.P.G.; Pires, T.; Santos, J.; Gouveia, B.P.; Fernandes, P.R. Permeability versus Design in TPMS Scaffolds. Materials 2019, 12, 1313. [CrossRef] [PubMed]

24. Zhao, F.; van Rietbergen, B.; Ito, K.; Hofmann, S. Flow rates in perfusion bioreactors to maximise mineralisation in bone tissue engineering in vitro. J. Biomech. 2018, 79, 232-237. [CrossRef] [PubMed]

25. Zaharin, H.; Abdul Rani, A.; Azam, F.; Ginta, T.; Sallih, N.; Ahmad, A.; Yunus, N.; Zulkifli, T. Effect of Unit Cell Type and Pore Size on Porosity and Mechanical Behavior of Additively Manufactured Ti6Al4V Scaffolds. Materials 2018, 11, 2402. [CrossRef]

26. Bobbert, F.S.L.; Lietaert, K.; Eftekhari, A.A.; Pouran, B.; Ahmadi, S.M.; Weinans, H.; Zadpoor, A.A. Additively manufactured metallic porous biomaterials based on minimal surfaces: A unique combination of topological, mechanical, and mass transport properties. Acta Biomater. 2017, 53, 572-584. [CrossRef]

27. Guedes, J.M.; Kikuchi, N. Preprocessing and postprocessing for materials based on the homogenization method with adaptive finite element methods. Comput. Methods Appl. Mech. Eng. 1990, 83, 143-198. [CrossRef]

28. Terada, K.; Ito, T.; Kikuchi, N. Characterization of the mechanical behaviors of solid-fluid mixture by the homogenization method. Comput. Methods Appl. Mech. Eng. 1998, 153, 223-257. [CrossRef]

29. Dias, M.R.; Fernandes, P.R.; Guedes, J.M.; Hollister, S.J. Permeability analysis of scaffolds for bone tissue engineering. J. Biomech. 2012, 45, 938-944. [CrossRef]

30. Marino, M.; Vairo, G.; Wriggers, P. Multiscale hierarchical mechanics in soft tissues. Pamm 2015, 15, 35-38. [CrossRef]

31. Daish, C.; Blanchard, R.; Pirogova, E.; Harvie, D.J.E.; Pivonka, P. Numerical calculation of permeability of periodic porous materials: Application to periodic arrays of spheres and 3D scaffold microstructures. Int. J. Numer. Methods Eng. 2019, 118, 783-803. [CrossRef]

32. Campos Marin, A.; Grossi, T.; Bianchi, E.; Dubini, G.; Lacroix, D. $\mu$-Particle tracking velocimetry and computational fluid dynamics study of cell seeding within a 3D porous scaffold. J. Mech. Behav. Biomed. Mater. 2017, 75, 463-469. [CrossRef] [PubMed]

33. Mccoy, R.J.; Jungreuthmayer, C.; O’Brien, F.J. Influence of flow rate and scaffold pore size on cell behavior during mechanical stimulation in a flow perfusion bioreactor. Biotechnol. Bioeng. 2012, 109, 1583-1594. [CrossRef] [PubMed]

34. Lacroix, D.; Prendergast, P.J. A mechano-regulation model for tissue differentiation during fracture healing: Analysis of gap size and loading. J. Biomech. 2002, 35, 1163-1171. [CrossRef]

(C) 2020 by the authors. Licensee MDPI, Basel, Switzerland. This article is an open access article distributed under the terms and conditions of the Creative Commons Attribution (CC BY) license (http://creativecommons.org/licenses/by/4.0/). 